\title{
Study on Partial Factor of Load for Reinforced Concrete Columns
}

\author{
Zhengjie Cheng $(\mathbb{D}$ and Jitao Yao \\ School of Civil Engineering, Xi'an University of Architecture and Technology, Xi'an, China \\ Correspondence should be addressed to Zhengjie Cheng; chengzhengjie_1995@163.com
}

Received 10 November 2020; Revised 14 December 2020; Accepted 24 December 2020; Published 15 January 2021

Academic Editor: Maria Patrizia Pera

Copyright (c) 2021 Zhengjie Cheng and Jitao Yao. This is an open access article distributed under the Creative Commons Attribution License, which permits unrestricted use, distribution, and reproduction in any medium, provided the original work is properly cited.

\begin{abstract}
At present, the design method of components is still a partial factor design method, and the partial factor value is related to the load value. Because the partial factor has a great influence on the safety of engineering structure, it has been adjusted many times in the process of organization of the code. In order to be basically equivalent to European and American reliability standards and to conform to China's national conditions and national policies, the Unified standard for reliability design of building structures is revised (i.e., the partial factor of permanent action and variable action was adjusted). Although the concept of factor of safety is commonly used in structure design practice to cover all the unexpected risks, there are some disadvantages to its direct use in structural reliability analysis. For example, the eccentricity of compression members is random, which will lead to the change in resistance parameters of compression members, rather than the fixed value specified in the code. However, the random variation in eccentricity is not considered in the code. So, in this paper, the partial factors of eccentrically loaded members are studied by considering the statistical parameter information of members with random eccentricity. This paper studies the partial factors of different types of components in different ratios of live load effect to dead load effect, and some recommendations are proposed to obtain safer designs. Finally, Monte Carlo simulation method is used to analyze the reliability of the eccentric member. The research results show that the value of partial factors of structure proposed in this paper is reasonable.
\end{abstract}

\section{Introduction}

At present, the reliability method of structural design is still the partial factor design method based on probability, the partial factor method is to express the design value of each variable as a simple function of standard value and partial factor, and the value of partial factors is obtained by an enumeration method [1].

The statistical parameters of resistance and load action determine the value of partial factor.

In the 1980s, when the code was compiled in China, according to the action probability characteristic and statistical parameters, the partial factor was determined [2]. With the increase in the load characteristic value in load code for design of building structures 2001 (GB50009-2001) [3], the partial factor of load has been changed accordingly [3]. Based on the 2001 version of the Unified standard for reliability design of building structures [4] (GB50068-2018), considering the practical engineer experience of nearly ten years, the 2019 version of the Unified standard for reliability design of building structures (GB50068-2018) is officially implemented.

In the basic load combination, the 2019 version of the Unified standard for reliability design of building structures no longer distinguishes the action combination of permanent load control or variable load control. The partial factor of permanent actions is adjusted from 1.2 or 1.35 to 1.3 , the partial factor of variable actions is adjusted from 1.4 to 1.5 , and the partial factor of prestressed is adjusted from 1.3. The specific values are listed in Table 1.

Compared with foreign codes, it is found that the adjusted partial factor of action is the same value as the American and European codes, and the safety level of new structures has been improved. However, the evaluation of existing structure is different from the design of new structure; if the new partial factor is still used in the evaluation of existing structure, the reliability index of structure has been greatly improved, and the increase in 
TABle 1: Partial factors of permanent and variable actions.

\begin{tabular}{|c|c|c|c|}
\hline & 2001 version & & 2019 version \\
\hline$\gamma_{\mathrm{G}}$ & $\begin{array}{l}\text { Variable load control } \\
\text { Permanent load control }\end{array}$ & $\begin{array}{c}1.2 \\
1.35\end{array}$ & 1.3 \\
\hline$\gamma_{\mathrm{Q}}$ & 1.4 & & 1.5 \\
\hline
\end{tabular}

analysis results will lead to some components that need to be strengthened without reinforcement, which will cause certain economic losses. This is mainly because the partial load factor is closely related to the load statistical parameters. The load partial factors change with the change in the load statistical parameters. In particular, the probability characteristics of variable actions (such as floor and roof live loads) are not immutable, so it is not reasonable to directly use the load statistical parameters specified in the code when evaluating the safety of existing structures. Therefore, it is difficult to judge whether the reliability level of the existing structure still meets the requirements when the safety assessment is carried out according to the partial load factor and characteristic value given by the code.

Considering the importance of partial factors in structural analysis, a lot of research has been done on this problem $[5,6]$. For the concrete eccentricity column, consider that the partial factor of resistance will change with the change in eccentricity. Therefore, by summarizing the papers of load statistics in recent years, this paper studies the change in reliability of reinforced concrete components under the change in load partial factor and compares it with the reliability index calculated by the 2019 version code.

\section{Probability Model of Loads and Resistance}

2.1. Probability Distribution of Action. Due to the variable characteristics of load, the study of characteristic value of load has been uninterrupted. The inferred value of load characteristic value has a great influence on the safety of engineering structure. When the inferential value is too large, it will cause economic waste. If the inferential value is too small, it may lead to early failure of the structure in service. From 1974 to 1981, in order to accurately describe the statistical parameter characteristics of loads, a lot of statistical work was carried out by several scientific research, design, construction, and university units during the preparation of unified standard for design of building structures (GB J68-1984) in China. The statistical parameters of mean variance of dead load, live load of residential and office buildings, wind load, and snow load were obtained, where the characteristic value of load $L_{\mathrm{k}}=\left(1.5 \mathrm{kN} / \mathrm{m}^{2}\right)$ in the code [7]. With the development of China's construction industry in the 1990s, the use of the load statistical parameters determined at that time cannot meet the current requirements for the safety of engineering structures. According to the new observation data, the standard value of floor live load in code for design of building structures (GB50009-2001) is adjusted to $L_{\mathrm{k}}=\left(2.0 \mathrm{kN} / \mathrm{m}^{2}\right)$, and the corresponding coefficient of mean of live load ratio is 0.75 , where the mean coefficient is $\chi=\left(\mu / L_{\mathrm{k}}\right)$, and the return period of the basic value of wind and snow load is changed from once in 30 years to once in 50 years. Since the change in load in 2001, there are few large-scale statistics on the parameters of load. At present, the research methods of load parameters are basically small sample inference methods, and they only aim at a specific city or a specific structural component. Through the analysis of its statistical parameters, small sample inference has certain rationality [8-12]. The values of the load statistical parameters obtained by the code and this paper are given, as shown in Table 2. The characteristic values in the statistical data are calculated with the same assurance rate (97.4) as the same code.

The live load follows the Gumbel distribution. According to the properties of Gumbel distribution, the average value and standard deviation of load distribution in a certain period have the following relations with the average value and standard deviation of load distribution at any time point:

$$
\begin{aligned}
\mu_{\mathrm{Q}_{\mathrm{T}}} & =\mu_{\mathrm{Q}}+\ln \left(\frac{T}{T_{0}}\right) * \frac{\sqrt{6} \sigma_{\mathrm{L}}}{\pi}, \\
\sigma_{\mathrm{L}_{r}} & =\sigma_{\mathrm{L}} .
\end{aligned}
$$

Therefore, the coefficient of mean and characteristic value can also be obtained by calculation for the components with a design service life of 25 years and 100 years. The results are as follows.

When the design service life and design reference period of the structure are different, it is necessary to introduce the action adjustment coefficient to adjust the load. Because the variable action obeys the extreme value I distribution, the calculation formula of the action adjustment coefficient is

$$
\gamma_{\mathrm{L}}=1+\frac{\sqrt{6}}{\pi} \frac{\sigma_{\mathrm{Q}_{T}}}{\mathrm{Q}_{\mathrm{k}}} \ln \left(\frac{T_{\mathrm{L}}}{T}\right)=1+0.7797 \chi_{\mathrm{Q}} \delta_{\mathrm{Q}} \ln \left(\frac{T_{\mathrm{L}}}{T}\right) .
$$

For members with design service life of 25 years and 100 years, respectively, the corresponding adjustment factors are $\gamma_{L}=0.9267$ vs 1.0733 .

The action is divided into permanent action and variable action [13]. The permanent action is assumed to be normally distributed with a coefficient of variation $\left(\delta_{G}\right) 0.074$ and a coefficient of mean $\chi_{G}=\left(\mu_{G} / G_{k}\right) 1.06$.

\subsection{Resistance Model of Reinforced Concrete Components.}

For eccentrically loaded columns with cross sections subjected to combined bending and thrust, the strength is determined by an interaction relationship between axial force $P$ and moment $M$. According to the eccentricity, reinforced concrete components can be divided into axial compression, eccentric compression, and flexural members. Through the interaction diagram analysis of eccentric compression components, axial compression and flexural members can be regarded as special cases of eccentric compression members (eccentricity is zero or $\infty$ ). The RC cross section used in the following analyses is shown in Figure 1. 
TABle 2: Load statistical parameter.

\begin{tabular}{|c|c|c|c|c|c|c|}
\hline \multirow{2}{*}{ Type of load } & & & \multicolumn{2}{|c|}{ GB 50068-2001 } & \multicolumn{2}{|c|}{ Statistical } \\
\hline & & & Mean & $\begin{array}{l}\text { Standard } \\
\text { deviation }\end{array}$ & Mean & $\begin{array}{l}\text { Standard } \\
\text { deviation }\end{array}$ \\
\hline \multirow{6}{*}{$\begin{array}{l}\text { Floor live load of residential } \\
\text { building }\end{array}$} & \multirow{2}{*}{ Any moment } & Persistent live load & 0.504 & 0.162 & 0.334 & 0.124 \\
\hline & & Temporary live load & 0.468 & 0.252 & 0.371 & 0.167 \\
\hline & \multirow{2}{*}{$\begin{array}{l}\text { Design reference } \\
\text { period }\end{array}$} & Persistent live load & 0.707 & 0.162 & 0.49 & 0.124 \\
\hline & & Temporary live load & 0.784 & 0.252 & 0.58 & 0.167 \\
\hline & Any moment & $\begin{array}{l}\text { Coefficient of mean of a } \\
\text { variable }\end{array}$ & 0.644 & 0.3 & 0.652 & 0.208 \\
\hline & $\begin{array}{l}\text { Design reference } \\
\text { period }\end{array}$ & Characteristic values & & 2.0 & & 1.4 \\
\hline
\end{tabular}

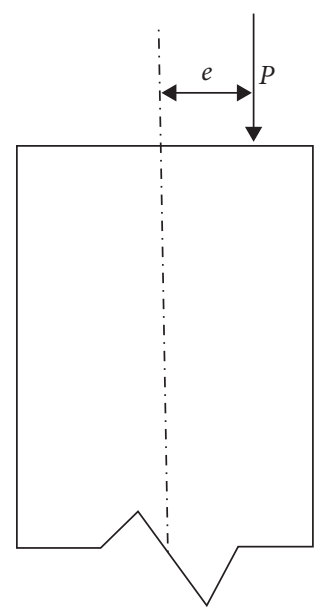

Figure 1: Eccentrically loaded reinforced concrete columns.

For reinforced concrete components, the coefficient of mean and variation coefficient specified in the specification are shown in Table 3.

$$
\begin{array}{r}
\chi=\frac{\mu_{X}}{X_{k}}, \\
\delta_{X}=\frac{\sigma_{X}}{\mu_{X}},
\end{array}
$$

where coefficient of mean is generally expressed by $\chi$ and variation coefficient by $\delta$.

In order to express the results intuitively, histogram is used to represent the statistical parameters, as shown in Figure 2.

According to the data analysis in Table 4, from the axial compression member to the flexural member, the average coefficient is reduced by $15 \%$ and the coefficient of variation is reduced by $41 \%$, which shows that coefficient of mean of eccentric compression component considered in the current code of China is imperfect, and the resistance statistical parameter does not consider the change in eccentricity resistance [14]. The same problem also appeared in foreign codes. Mirza obtained the change in resistance statistical parameters under different eccentricities and different reinforcement ratios [15].
According to the code for design of concrete structures, the calculation formula of eccentrically compressed members is as follows [16].

Large eccentric compression:

$$
\begin{aligned}
& N_{\mathrm{u}} \leq\left(\alpha_{1} f_{\mathrm{c}} \alpha_{\mathrm{s}} b h_{0}^{2}+\frac{\left.f_{\mathrm{y}}^{\prime} A_{\mathrm{s}}^{\prime}\left(h_{0}-a_{\mathrm{s}}^{\prime}\right)\right)}{e},\right. \\
& \alpha_{s}=\xi\left(1-\frac{\xi}{2}\right) .
\end{aligned}
$$

Small eccentric compression:

$$
N_{\mathrm{u}} \leq\left(\alpha_{1} f_{\mathrm{c}} b x\left(h_{0}-\frac{x}{2}\right)+\frac{\left.f_{\mathrm{y}}^{\prime} A_{\mathrm{s}}^{\prime}\left(h_{0}-a_{\mathrm{s}}^{\prime}\right)\right)}{e} .\right.
$$

The meaning of the variable is the same as that of the $r$ code for design of concrete structures. By using the formula and the probability distribution of each variable, different eccentricities $(e / h)$ are taken for the columns of eccentrically compressed members, the Monte Carlo method is used to calculate, and finally, the corresponding mean coefficient is obtained.

The calculation formula is as follows:

$$
\chi_{\mathrm{R}}=\frac{N_{\mathrm{u}}}{N_{\mathrm{u}_{\mathrm{k}}}},
$$

where $N_{\mathrm{u}}$ is the value calculated by formula and $N_{\mathrm{u}_{\mathrm{k}}}$ is the result calculated by characteristic value.

The calculation process is shown in Figure 3.

Based on this research method, Jiang et al. calculated the resistance mean value and variation coefficient under different eccentricities and different reinforcement ratios [14]. The calculation results are shown in Table 5.

\section{Partial Factors}

At present, there are two methods to determine the partial factor $[17,18]$ : one is the design value method, and the other is the optimization method, which is calculated after obtaining the parameters of load and resistance. 
TABLE 3: Parameters of reinforced concrete components.

\begin{tabular}{|c|c|c|c|c|}
\hline Structural component type & Stress status & Coefficient of mean & Variation coefficient & Safety factors \\
\hline \multirow{4}{*}{ Reinforced concrete component } & Axial compression & 1.33 & 0.17 & 1.231 \\
\hline & Small eccentric compression & 1.30 & 0.15 & 1.129 \\
\hline & Large eccentric compression & 1.16 & 0.13 & 1.143 \\
\hline & Bending & 1.13 & 0.10 & 1.127 \\
\hline
\end{tabular}

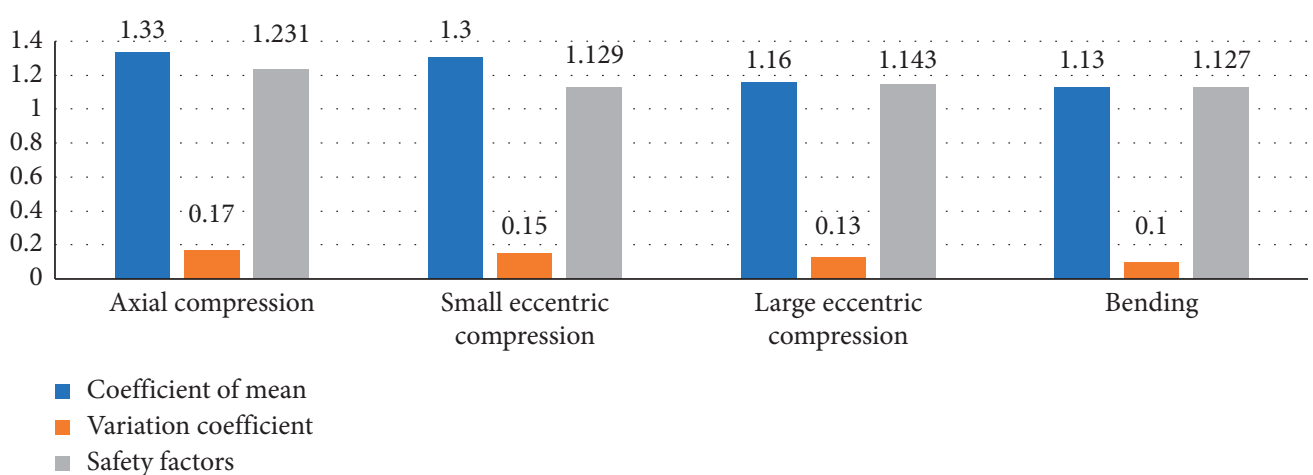

FIgURE 2: Statistical parameters.

3.1. Design Value Method. Assume that $X_{1}, X_{2}, \ldots, X_{n}$ is the $n$ variable parameters in the structure, the probability distribution and statistical parameters of the variables are known, and the function of the structure is expressed as follows:

$$
Z=g\left(X_{1}, X_{2}, \ldots, X_{n}\right)
$$

In the form of practical expression, equation (4) can be written as

$$
g\left(x_{1 d}, x_{2 d}, \ldots, x_{n d}\right) \geq 0
$$

where $x_{1 d}, x_{2 d}, \ldots, x_{n d}$ is the design value of variable $X_{1}, X_{2}, \ldots, X_{n}$.

According to the form of partial factor, equation (4) can also be written as follows:

$$
g\left(\gamma_{x_{1}} x_{1 k}, \gamma_{x_{2}} x_{2 k}, \ldots, \gamma_{x_{n}} x_{n k}\right) \geq 0,
$$

where $\gamma_{x_{1}}, \gamma_{x_{2}}, \ldots, \gamma_{x_{n}}$ is the partial factor for variable $X_{1}, X_{2}, \ldots, X_{n}$ and $x_{1 k}, x_{2 k}, \ldots, x_{n k}$ is the characteristic value of $X_{1}, X_{2}, \ldots, X_{n}$.

According to the definition of check point method, the design value of variable shall be taken as the check point value $x_{1}^{*}, x_{2}^{*}, \ldots, x_{n}^{*}$ of variable, so the design value of variable can be expressed as follows:

$$
x_{i \mathrm{~d}}=x_{i}^{*}=F_{\mathrm{x}_{i}}^{-1}\left[\Phi\left(\beta_{T} \alpha_{X_{i}}\right)\right], \quad(i=1,2, \ldots, n),
$$

where $F_{\mathrm{x}_{i}}^{-1}(\cdot)$ is the inverse function of probability distribution of variable. $\beta_{T}$ is the target reliability index values, and the values under different safety levels are shown in Table 6. $\alpha_{X_{i}}$ is the sensitivity coefficient, which can be calculated by an iterative method.

Therefore, the calculation formula of partial factors expressed by design value and eigenvalue is obtained:

$$
\gamma_{x_{i}}=\frac{x_{i \mathrm{~d}}}{x_{\mathrm{k}}}=\frac{F_{x_{i}}^{-1}\left[\Phi\left(\beta_{T} \alpha_{X_{i}}\right)\right]}{x_{\mathrm{k}}} .
$$

Since the distribution of resistance, dead load, and live load, respectively, obeys the lognormal distribution, normal distribution, and extreme I-type distribution, the above formula can be written as follows:

$$
\begin{aligned}
& \gamma_{\mathrm{R}}=\frac{R_{\mathrm{d}}}{R_{\mathrm{k}}}=\frac{1}{\chi_{R} \delta_{R} \exp \left(\alpha_{R} \delta_{R} \beta_{\mathrm{T}}\right)}, \\
& \gamma_{\mathrm{G}}=\frac{G_{\mathrm{d}}}{G_{\mathrm{k}}}=\frac{\mu_{G}\left(1+\alpha_{G} \delta_{G} \beta_{\mathrm{T}}\right)}{\left(\mu_{G} / \chi_{G}\right)}, \\
& \gamma_{\mathrm{Q}_{i}}=\frac{Q_{\mathrm{id}}}{Q_{\mathrm{k}}}=\chi_{\mathrm{Q}_{i}}\left(1-0.7797 \delta_{\mathrm{Q}_{i}}\left\{0.5772+\ln \left[-\ln \Phi\left(\alpha_{\mathrm{Q}_{i}} \beta_{T}\right)\right]\right\}\right) .
\end{aligned}
$$

Since there are usually several live loads, here is the general formula, is the type of $\operatorname{load}(i=1,2, \ldots, n)$. The calculated partial factor values are as follows in Table 7.

3.2. Optimization Method. When using the optimization method to calculate the partial factor, the design expressions 
TABLE 4: Load statistical parameters corresponding to different design years.

\begin{tabular}{|c|c|c|c|c|c|c|}
\hline \multirow{2}{*}{ Type of load } & & & \multicolumn{2}{|c|}{$\mathrm{T}=25$} & \multicolumn{2}{|c|}{$\mathrm{T}=100$} \\
\hline & & & Mean & $\begin{array}{l}\text { Standard } \\
\text { deviation }\end{array}$ & Mean & $\begin{array}{l}\text { Standard } \\
\text { deviation }\end{array}$ \\
\hline \multirow{6}{*}{$\begin{array}{l}\text { Floor live load of } \\
\text { residential building }\end{array}$} & \multirow{2}{*}{ Any moment } & Persistent live load & 0.334 & 0.162 & 0.334 & 0.124 \\
\hline & & Temporary live load & 0.371 & 0.252 & 0.371 & 0.167 \\
\hline & \multirow{2}{*}{ Design reference period } & Persistent live load & 0.423 & 0.162 & 0.557 & 0.124 \\
\hline & & Temporary live load & 0.490 & 0.252 & 0.671 & 0.167 \\
\hline & Any moment & Coefficient of mean of a variable & 0.625 & 0.208 & 0.671 & 0.208 \\
\hline & Design reference period & Characteristic values & \multicolumn{2}{|c|}{1.317} & \multicolumn{2}{|c|}{1.498} \\
\hline
\end{tabular}

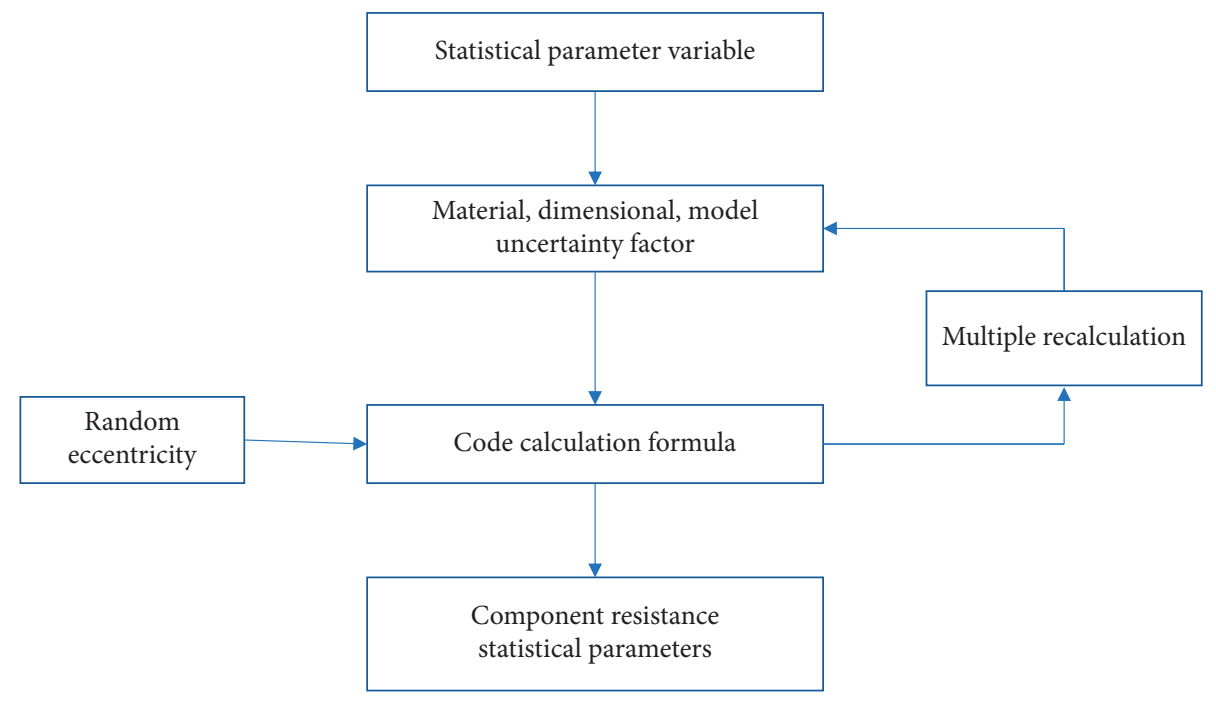

Figure 3: Flowchart for the calculation of the statistical parameters.

TABLE 5: Calculated characteristic parameters of reinforced concrete components.

\begin{tabular}{lccc}
\hline Structural component type & Stress status & Coefficient of mean & Variation coefficient \\
\hline & Axial compression & 1.33 & 0.17 \\
Reinforced concrete component & Small eccentric compression & 1.3296 & 0.158 \\
& Large eccentric compression & 1.2108 & 0.111 \\
& Bending & 1.13 & 0.10 \\
\hline
\end{tabular}

TABle 6: Target reliability index values.

\begin{tabular}{lccc}
\hline Damage type & First class & Safety level & Second class \\
Ductile failure & 2.7 & 3.2 & 3.7 \\
Brittle failure & 3.2 & 3.7 & 4.2 \\
\hline
\end{tabular}

of components and structures remain unchanged, but the partial factor of variables is no longer directly expressed as the function of target reliability. First, assume multiple groups of partial factors, calculate the reliability index under the assumed partial factors, and compare it with the target reliability index. After multiple groups of calculation, determine the value close to the target reliability index of a group of calculated reliability indexes: 
TABLE 7: Partial factor value.

\begin{tabular}{|c|c|c|c|c|c|}
\hline \multirow{3}{*}{ Structural component type } & \multicolumn{5}{|c|}{ Partial factor } \\
\hline & \multicolumn{2}{|c|}{ Design method } & \multicolumn{2}{|c|}{ Optimization method } & \multirow{2}{*}{ Resistance } \\
\hline & Dead load & Floor live load & Dead load & Floor live load & \\
\hline Axial compression & & & & & 1.1619 \\
\hline Small eccentric compression & & & & & 1.127 \\
\hline Large eccentric compression & 1.126 & 1.0533 & 1.2 & 1.5 & 1.0973 \\
\hline Bending & & & & & 1.1431 \\
\hline
\end{tabular}

$$
H=\sum \omega_{i}\left(\beta_{i}-\beta_{T}\right)^{2}
$$

where $\omega_{i}$ is the weight coefficient, $\beta_{i}$ is the reliability index calculated by the assumed partial factor, and $H$ is the difference between the reliability index and target reliability index.

The calculation process is as follows:

(1) Select the structural components and determine the safety level.

(2) For the selected structural members, the resistance design values under any set of assumed partial coefficients are determined (in the process of assumption, the values of partial coefficients should keep the same proportion).

(3) Calculate the reliability index of the selected structural members under the combination.

(4) Compared with the target reliability indexes under different security levels, the value of $H$ is determined. The smaller the $H$ is, the better the assumed partial coefficient is.

Through calculation, the partial factors of eccentrically loaded RC compression member under the two methods are obtained. The calculation results are shown in Table 7.

3.3. Load Adjustment Coefficient and Structure Importance Coefficient. Since the characteristic value of load should not be changed with the change in design service life, the requirement of increasing the load value of structure can be achieved by the load characteristic value $L_{\mathrm{k}}$ multiplying the load adjustment coefficient $\gamma_{\mathrm{T}}[19]$ :

$$
\begin{aligned}
\gamma_{\mathrm{T}} & =\frac{L_{\mathrm{kT}}}{L_{\mathrm{k}}}, \\
L_{\mathrm{kT}} & =\mu_{\mathrm{L}_{\mathrm{T}}}+\alpha \sigma_{\mathrm{L}_{\mathrm{T}}},
\end{aligned}
$$

where $L_{\mathrm{kT}}$ and $\mu_{\mathrm{L}_{\mathrm{T}}}$ are the average value of load characteristic value and average of load maximum value when the design life is $\mathrm{T}$ and $\alpha$ is the coefficient under the same guarantee rate as the specification. According to the specification, the assurance rate is $97.4 \%$ and $\alpha=2.37$.

It can be seen from the calculation that, for the structural components with a design life of 100 years, $\gamma_{\mathrm{T}}=1.07$, and for the structures with a design life of 25 years, $\gamma_{\mathrm{T}}=0.94$. It is equivalent to the structural importance coefficient of 1.1-0.9 considered in the current code of China, which can also be assumed as the structural importance coefficient in the analysis.

In addition, for the determination of the structural importance coefficient, the value can also be taken according to the optimization method. For structures with safety classes I and III, the partial load factor is taken as 1.2 and 1.5 as shown above, which are solved according to the target reliability index considered in the current code. In order to meet the minimum target reliability index requirements under different load ratios, the structural importance coefficient is taken as $\gamma_{0}=1.13$ and 1 when the design service life is 100 and 25 years, respectively. Compared with the abovementioned load adjustment coefficient, the values are similar.

\section{Examples of Application}

A simple example illustrates how the load partial factors values obtained from the study are applied for the assessment of an existing structure.

The safety level of reinforced concrete large eccentric compression column is designed as second. Considering a load combination form (dead load + live load), using the partial factor and load statistical parameters in the paper, the reliability index of the component is 3.3631 and 4.5339, and the reliability index calculated by the parameters in the revised 2019 code is 4.3979 . The calculation results show that the partial factors proposed by the design value method and the optimization method meet the requirements of reliability design specification. Table 8 shows the reliability indexes under different load ratios. 
TABLe 8: Reliability index under different load ratios.

\begin{tabular}{lcccccc}
\hline & \multicolumn{7}{c}{ Ratio of floor live load effect to dead load effect } & \multicolumn{1}{c}{ Mean } \\
& 0.1 & 0.25 & 0.5 & 1.0 & 1.5 & 2.0 \\
\hline Design value method & 3.0116 & 3.336 & 3.5654 & 3.5069 & 3.4122 & 3.3463 \\
Optimization method & 4.5924 & 4.9181 & 4.7851 & 4.4543 & 4.2829 & 4.1826 \\
2019 version code & 3.6984 & 4.2293 & 4.6383 & 4.6055 & 4.6055 & 4.5595 \\
\hline
\end{tabular}

\section{Conclusions}

Based on the limit state design expression and probability method, considering the structural resistance and load characteristics, the deterministic optimization design is carried out. The results are consistent with the engineering judgment. The results of this paper are helpful to the safety assessment of existing structures. In addition, since the resistance attenuation is not considered in the analysis, it is impractical to assume that the resistance remains unchanged during the service period, so the influence of resistance reduction factor should be added in the subsequent study.

\section{Notations}

$\beta$ : $\quad$ Reliability index

$R: \quad$ Resistance

$S$ : Action effect

$G$ : Permanent action

Q: Variable action

$x$ : Variable

$x_{k}$ : Characteristic value of variable

$\gamma_{x}$ : Partial safety factors for variable

$\gamma_{R}$ : Partial safety factors for the resistance

$\gamma_{0}$ : Coefficient for importance of the structure

$\gamma_{G}$ : Partial factor for permanent actions

$\gamma_{Q_{i}}$ : Partial factors for variable actions

$S_{G_{\mathrm{k}}}$ : Characteristic value of the effect of the permanent action

$S_{Q_{i k}}$ : Characteristic value of the effect of the variable action

$R(\cdot)$ : Function of the resistance for structures

$\rho$ : $\quad$ Ratio of floor live load effect to dead load effect

$\xi$ : $\quad$ Ratio of floor live load effect to wind or snow load effect

$\mu_{X}:$ Mean of a variable

$X_{\mathrm{k}}$ : Characteristic values of a variable

$\chi$ : Coefficient of mean of a variable $\chi=\left(\mu / X_{k}\right)$.

\section{Data Availability}

The data used to support the findings of this study are included within the article and $[3,4]$.

\section{Conflicts of Interest}

The authors declare that they have no conflicts of interest.

\section{Acknowledgments}

This work was supported by the National Key Research and Development Projects (Program 2016YFC0701301-01).

\section{References}

[1] H. S. Ang, Probability Concepts in Engineering Planning and Design, Risk \& Reliability, John Wiley \& Sons, Inc, New York, NY, USA, 2007.

[2] M. S. Li, Z. M. Shao, and K. Ma, "A methodology of probability-based limit states design-some concepts on the draft of "common unified standard for building structures design" in China codes research department, institute of building structures, Chinese academy of building research," Journal of Building Structures, vol. 4, pp. p3-p20, 1981.

[3] Housing and Urban-Rural Development of the People's Republic of China, Load Code for the Design of Building Structures (GB50009-2001), China Architecture and Building Press, Beijing, China, 2001.

[4] Housing and Urban-Rural Development of the People's Republic of China, Unified Standard for Reliability Design of Building Structures (GB50068-2001), China Architecture and Building Press, Beijing, China, 2001.

[5] G. Shi, Y. Gao, and X. Wang, "Material properties and partial factors for resistance of low yield point steels in China," Construction and Building Materials, vol. 209, pp. 295-305, 2019.

[6] E. D. Smedt, M. Mollaert, and R. Caspeele, "Reliability-based calibration of partial factors for the design of membrane structures," Engineering Structures, vol. 214, Article ID $110632,2020$.

[7] J. X. Gong and W. W. Wei, Reliability Design Principle of Engineering Structure, Mechanical Industry Press, Beijing, China, 2007.

[8] J. H. Li, Z. M. Lin, and M. S. Li, Probability Limit State Design of Building Structure, China Construction Industry Press, Beijing, China, 1990.

[9] C. L. Jia, Statistical Inference Methods for Characteristic Value of Floor Live Load on Minor Sample, Xi'an University of Architecture and Technology, Xi'an, China, 2013.

[10] J. G. Niu and D. T. Niu, "Investigation and statistical analysis of floor load of residential structure," Journal of Xi'an University of Architecture and Technology (Natural Science Edition), vol. 38, no. 2, pp. 214-220, 2006.

[11] J. T. Yao, H. Gu, and J. S. Hou, "Probability model of floor live load and floor reliability analysis of industrial buildings," Journal of Applied Mechanics, vol. 35, no. 6, pp. 1234-1240, 2018.

[12] S. J. Ge, "Survey and statistical analysis of live loads of residential buildings in the central plains region," Journal of Civil Engineering, 2006.

[13] A. Haldar and S. Mahadevan, Probability, Reliability, and Statistical Methods in Engineering Design, Wiley, New York, NY, USA, 2000.

[14] Y. B. Jiang, Q. Liao, and F. Peng, "Refined probabilistic model of resistance of RC eccentric compression members," Civil Architecture and Environmental Engineering, vol. 36, no. 4, pp. 15-21, 2014. 
[15] S. A. Mirza, "Reliability-based design of reinforced concrete columns," Structural Safety, vol. 18, no. 2-3, pp. 179-194, 1996.

[16] Housing and Urban-Rural Development of the People's Republic of China, Code for Design of Concrete Structures (GB 50010-2010), China Architecture and Building Press, Beijing, China, 2014.

[17] J. T. Yao, Z. F. Luo, and K. K. Cheng, "Design value method of assessing the existing structural reliability," Journal of $X i^{\prime}$ an University of Architecture and Technology, vol. 48, no. 1, pp. 18-23, 2016.

[18] International Organization for Standardization, International Standard: Bases for Design of Structures Assessment of Existing Structures, ISO13822:2010, International Organization for Standardization, Geneva, Switzerland, 2010.

[19] Z. H. Shi, "Design service life and structural importance coefficient of structure," Architectural Science, vol. 6, no. 6, pp. P32-P33, 2000. 